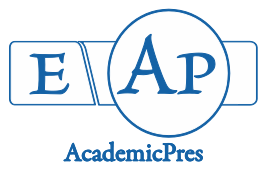

Shahrajabian MH et al. (2020)

Notulae Scientia Biologicae 12(2):197-207

DOI:10.15835/nsb12210725

Short Review

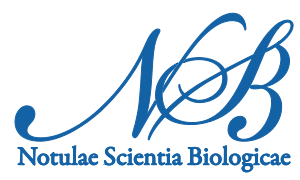

\title{
Chinese onion, and shallot, originated in Asia, medicinal plants for healthy daily recipes
}

\author{
Mohamad H. SHAHRAJABIAN ${ }^{1 a}$, Wenli SUN ${ }^{1 \mathrm{~b}}$, Qi CHENG ${ }^{1,2 *}$
}

\author{
${ }^{1}$ Chinese Academy of Agricultural Sciences, Biotechnology Research Institute, Beijing 100081, \\ China; hesamshahrajabian@gmail.com; sunwenli@caas.cn \\ ${ }^{2}$ Hebei Agricultural University, College of Life Sciences, Baoding, Hebei, 071000, China; Global Alliance of HeBAU-CLSe'HeQiS for \\ BioAl-Manufacturing, Baoding, Hebei 071000, China; chengqi@caas.cn ('corresponding author) \\ ${ }^{a, b}$ These authors contributed equally to the work
}

\begin{abstract}
Shallot is an important part of diet of many populations and there is long-held belief in their health enhancing properties. Shallots, like onions, are a member of the Allium family, but their flavor is richer, sweeter, yet more potent. The most important benefits of shallots are high source of antioxidants, improve heart health, cancer prevention, diabetes, anti-inflammatory, antimicrobial, might help fight obesity, and help to prevent or treat allergies. Shallots are a rich source of flavonoid antioxidants such as quercetin and kaempferol. They contain sulfur antioxidant compounds such as diallyl disulfide, diallyl trisulfide, and allyl propyl disulfide. Shallots hole proportionately more concentration of vitamins and minerals than in onions, especially vitaminA, pyridoxine, folates, thiamin, vitamin-C etc. Chinese onion has very complex nutritional composition and holds the better characteristics for its potential development as a food ingredient, source of antioxidant; it contains secondary metabolites such as flavonoids, particularly flavonols and anthocyanin, phytosterols and saponins. It is also one of the most important medicinal plant in Eastern Asia. It contains many vitamins and minerals and it is rich in sulphur amino acids. Chinese onion was found to possess a panoply of bioactive compounds and numerous pharmacological properties, including antimicrobial, antioxidant, analgesic, antiinflammatory, anti-diabetic, hypolipidemic, anti-hypertensive and immune-protective effects.
\end{abstract}

Keywords: Chinese onion; health benefits; shallot; traditional herbal plants

\section{Introduction}

The traditional healer plants provide health care services based on religious background, knowledge, culture, attitudes and beliefs (Shahrajabian et al., 2020a; Shen et al., 2020; Sun et al., 2020a,b). Both natural products and traditional medicines have great importance (Shahrajabian et al., 2019a,b,c). Traditional medicine refers to health practices, knowledge, approaches and beliefs incorporating plants and herbs based on both ancient and modern pharmaceutical science (Ogbaji et al., 2018; Shahrajabian et al., 2019d,e,f,g; Sun et al., 2019a,b). Traditional Asian medicine plays an important role in sustainable agriculture and food systems, it is also offers a holistic and significant approach to prevent diseases while making suitable usage of organic and 
herbal products (Soleymani and Shahrajabian, 2012; Ogbaji et al., 2013; Ge et al., 2018; Shahrajabian et al., 2018; Soleymani and Shahrajabian, 2018; Sun et al., 2019c; Shahrajabian et al., 2020b,c).The aim of this review is survey on the most important chemical constituent, health benefits and medicinal usage of shallot and Chinese onion.

\section{Shallot}

Shallots (Allium ascalonicum L.) are a perennial crop that is grown as an annual for its cluster of small bulbs or cloves. Shallots are valuable spices for both flavoring dishes and as medicinal plants (Swamy and Veere Gowda, 2006). Shallot is a hardy member of the onion family that is famous for its delicate, meaty, onion-like flavor. Persian shallot, a bulb producing plant from Alliaceae, is wildly growing plant collected for its bulbs, and it is called Mooseer in Farsi, are oval, white skinned and completely different from common shallot (Allium ascalonicum) (Ebrahimi et al., 2019). Persian shallot is native and endemic of Iran and grows as a wild plant across Zagross mountains at high elevations of different provinces from Northwestern to Southern of Iran with the climate of very cold to moderate cold (Moradi et al., 2013). Shallot is a major component of many Asian diets and is widely believed to be beneficial to health (Jalal et al., 2011). Tesfa et al. (2015) found that shallot can be a substitute where bulb onion does not do well, however, the production of shallot can be limited due to poor soil fertility, lack of improved production techniques, unimproved varieties and high post-harvest losses. Shallots are a unique vegetable that is used by domestic consumers as every day seasoning, raw materials of food industry, and medicine (Setyadjit and Sukasih, 2015). The most common diseases of shallots are downy mildew, bacterial soft rot and neck rot, and the most important insects are onion maggot and onion thrips. The benefit of shallot is as a source of carbohydrate, vitamin A, B, and C. 1-butene, 1-(methylthio)-(Z) (18.21\%), methyl methylthiomethyl disulfide (8.41\%), dimethyl tetrasulfide (6.47\%), piperitenone oxide (4.55\%) are the most abundant components of Persian shallot and comprised 37\% of the essential oil. Ebrahimi et al. (2008) showed that Iranian shallot landraces are important in mineral elements and essential fatty acids content and are recommended for human nutrition. Sittisart $e t$ al. (2017) showed that shallots extracts contained some polyphenols such as apigenin, gallic acid, catechin, quercetin, kaempferol and tannic acid which are famous compounds possessing antifungal activity. Golubkina et al. (2019) indicated that shallot is an excellent candidate for the health-centered strategy of producing functional foods with high levels of Se and antioxidants; and the usage of arbuscular mycorrhizal fungi and selenium application represent environmentally friendly strategies to enhance the overall yield and quality performances of shallot bulbs. Fattorusso et al. (2002) reported two new furostanol saponins, named ascalonicoside A1/A2 (1a/1b) and ascalonicoside B (4), respectively, along with compounds $2 \mathrm{a}$ and $2 \mathrm{~b}$. Phaiphan et al. (2019) discovered that heating and shallot supplementation can massively improve the quality of apple juice. Yin et al. (2006) suggested the use of shallot and scallion oils in food systems which may enhance lipid and microbial stability. Raeisi et al. (2016) concluded that the application of 3\% ajwain seed extract gave the best antioxidant and antimicrobial activities, as well as sensory, up to 15 days of storage, followed by $3 \%$ shallot fruit extract. Leelarungrayub et al. (2006) stated that organic solvent and aqueous extracts of garlic and shallot bulbs had significant antioxidant potential, as measured by decreases in free radicals and an ability to inhibit lipid oxidation. Wongmekiat et al. (2008) indicated the protective potential of shallot extract against CsA nephrotoxicity and suggest a significant contribution of its antioxidant property to this beneficial effect. Chen et al. (2011) have shown the potential of shallots for use in treating adenoviral infection activities. Krejcova $e t$ al. (2014) found that the important usage of Persian shallot for the treatment of inflammatory disorders. They have introduced 2-[(Methylthio)methyldithio] pyridine $N$-oxide with high anti-inflammatory effects. Falahati et al. (2011) indicated that crude juice of shallot has anti-candidal activity and might be promising in treatment 
of candidiasis. Kongkaew and Phichai (2010) found that dried shallot powder, which was effective at inhibiting the growth of Trichoderma spp. isolated from Yanagi mushroom. Jalal et al. (2011) found that Iranian shallot extracts appear to improve learning and memory impairments in fructose-fed rats. Shallot can be a candidate for prevention and treatment of many diseases related to inflammation and malignancy. Leelarungrayub et al. (2004) indicated that hexane-extract shallot had very high activity on protecting the human erythrocyte from radicals and is possible to be modified for medical plants or commercial product in the future. Sadat Hosseini et al. (2017) found that the Persian shallot extract could be considered as a potential candidate for production of drug for the prevention or treatment of human hepatoma. Shallot crude juice has antifungal activity and looks promising to be an alternative for chemical antifungal agents that have sometimes serious effects. Rattanachaikunsopon and Phumkhachorn (2009) reported that shallot oil inhibits pathogenic bacteria including Bacillus cereus, Camplobacter jejuni, Escherichia coli O 157:H7, Listeria monocytgenes, Salmonella enterica, Staphylococcus aureus, and Vibrio cholerae. Farajii et al. (2018) stated that the shallot extract was preferred in both terms of reducing microbial growth and suitable sensory properties. Fresh crude juice of shallot bulbs has markedly anti-fungal effect, and also shallot extract has more anti-saprophytes effect at $0.25 \%$ followed by $C$. albicans and dermatophytes. Kazemian et al. (2017) noted that hydroalcoholic shallot extract increases the number of germ cells in mice tested and helps amplify the sexual ability of male mice. Shallot as traditional medicine are for febrifuge, diabetes, blood sugar and blood cholesterol, prevents thickening and hardening of the blood vessels and ulcers (Setyadjit and Sukasih, 2015). Setyadjit and Sukasih (2015) also reported that shallot powder is widely used as an industrial raw material such as in snacks production, seasoning in cooking, and medicine. Persian shallot has been reported to have a range of health benefits which include anticarcinogenic, hypoglycemic, hypolipidemic, antioxidant, antibiotic properties, kidney and liver protective effects (Moradi et al., 2013). All in all, shallots have more antioxidants, minerals and vitamins than onions. They are a rich source of flavonoid antioxidants such as quercetin, kaempferol, etc. They contain sulfur antioxidant compounds as diallyl disulfide, diallyl trisulfide, and allyl propyl disulfide, which convert to allicin through enzymatic action following disruption of their cell surface while crushing, and chopping. Alicin reduces cholesterol production by inhibiting the $H M G$-CoA reductase enzyme in the liver cells. The phytochemical compounds allium and Allyl disulfide in eschalots have anti-mutagenic and anti-diabetic properties. Medicinal properties of Persian shallot are shown in Figure 1. The most important health benefits of shallots are indicated in Figure 2. Whole shallot plant is shown in Figure 3. 


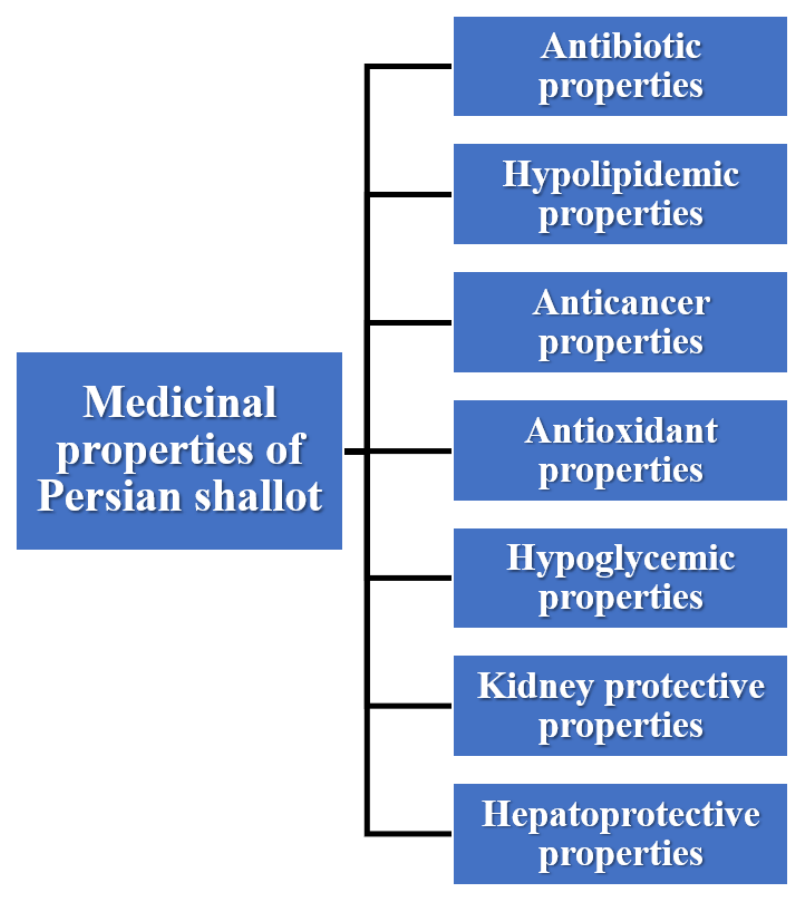

Figure 1. Medicinal properties of Persian shallot

$\begin{gathered}\text { The most important health } \\ \text { benefits of shallots }\end{gathered}$
$>$ Cut cancer risk
$>$ Improve heart health
$>$ Aid detoxification
$>$ Help control diabetes
$>$ Improve brain health
$>$ Help fight obesity
$>$ Help treat allergies
$>$ Boost bone health
$>$ Might maintain vision health
> Boost immunity
$>$ Improve skin health
$>$ Enhance abdominal health
$>$ Keep hair healthy

Figure 2. The most important health benefits of shallots 


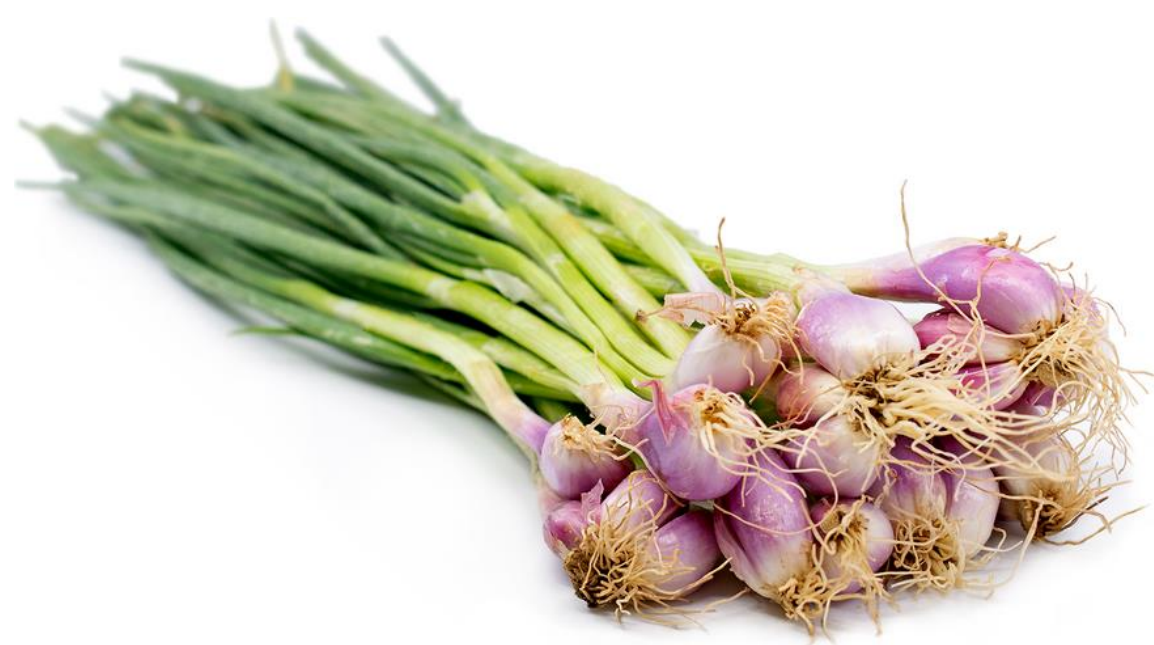

Figure 3. Whole shallot plant

\section{Chinese onion}

Traditional medicinal science in Asia, as a stand origin of Allium plants, is one of the high-born therapeutic systems in terms of the various herbals and age (Asemani et al., 2019). Allium species are supposed to be ones of the world's oldest cultivated vegetable. Most of the edible Allium species are native to the mountains of central Asia. The economically most important Allium crop species (common onion and garlic) are worldwide use as species, vegetables, and medicinal plant; and traditionally, they pay important role in the daily diet in Asia (Teshika et al., 2018). Chinese onion (A. chinense G. Don), also known as oriental onion, is an ancient vegetable native to China (Yan et al., 2009; Wang et al., 2019). In China, its bulbs are constantly served as sweet or sour pickles after steeped in sugar and brine, and it is also common to cook with other ingredients to afford various featured Chinese cuisine (He et al., 2018). Bulbs are purplish or grayish white and covered by a semi-transparent, dry membranous skin. They have a crisp texture and a strong onion-like but distinctive odor, and the leaves of Chinese onion grow up to $50 \mathrm{~cm}$ long and resemble those of chives but are angular rather than round and less erect. Whole plant local Chinese onion is presented in Figure 4.

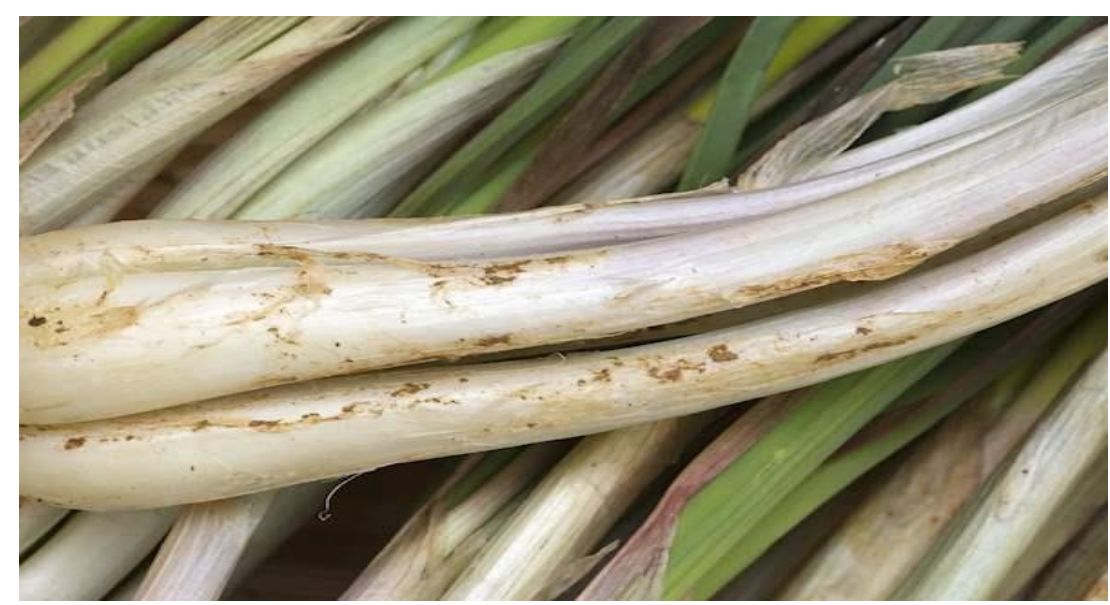

Figure 4. Whole plant of local Chinese onion 
Phytochemical investigates on Chinese onion have led to the isolation of sulfur-containing compounds which responsible for its onion-like flavor, nitrogen-containing constituents, and steroidal saponins (Wang $e t$ al., 2016). The plant-derived polyphenols from genus Allium, serve beneficial roles in humans. The most important health benefits of Chinese onion are shown in Figure 5.

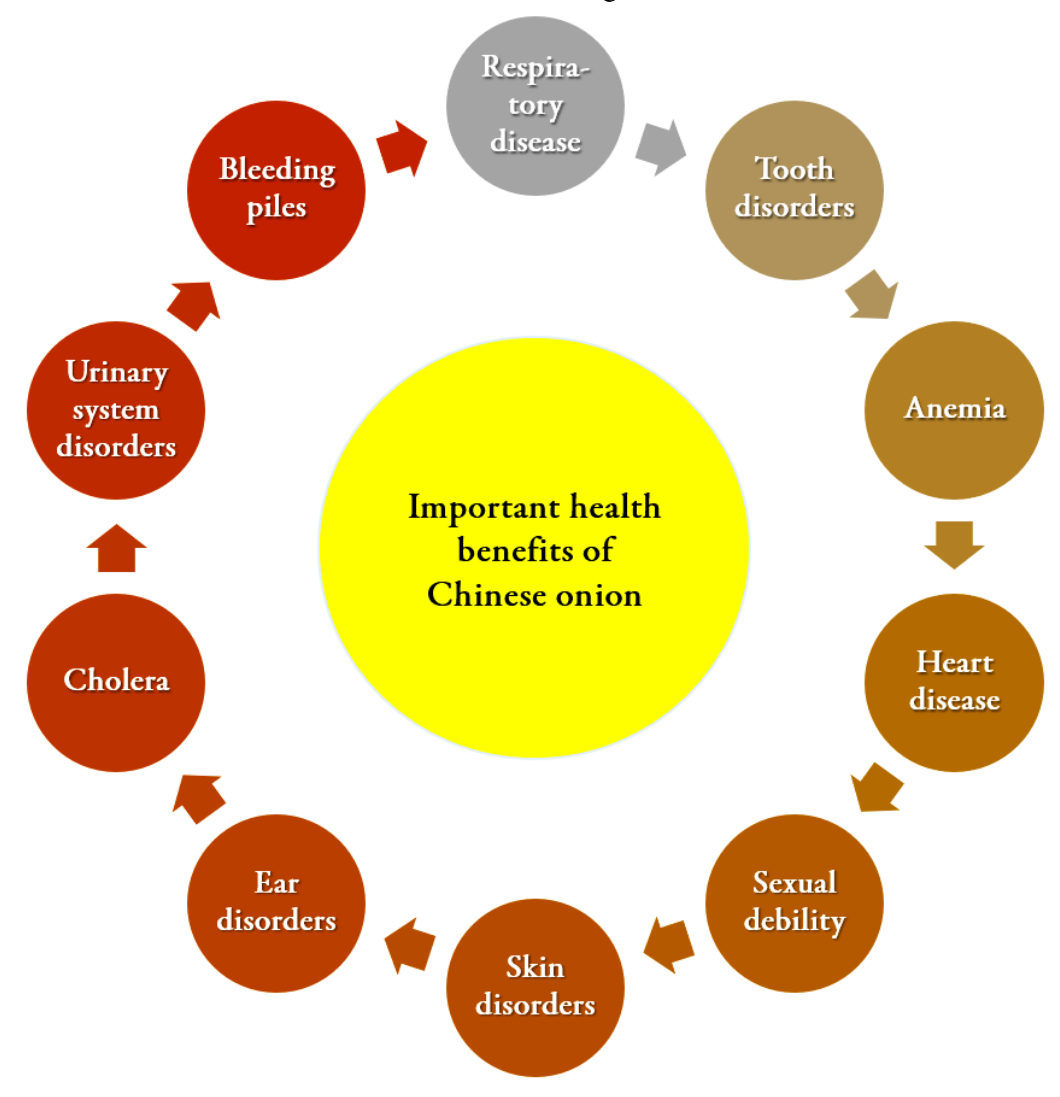

Figure 5. The most important health benefits of Chinese onion

The plant-derived phytochemical flavonols include quercetins and quercetin glycosides (Pan et al., 2018). Quercetins have been reported to exhibit anti-cancer and anti-inflammatory activities (Rohn et al., 2007). They have also reported that the bulbs of this plant are main source of a Chinese traditional medicine "Xiebai", which is used for the treatment for chest pain, stenocardia, and heart asthma. Chinese onion polysaccharides have attracted a great deal of concern to their therapeutic properties, especially anti-cancerous, anti-oxidant, anti-diabetic, anti-microbial properties and of course immunomodulatory role (Zhu et al., 2018). Flavonoids and organosulfur compounds are the two major classes of secondary metabolites found in Allium believe to promote beneficial health effects. Asemani et al. (2019) discovered that the phytochemical analysis of various Allium genus members showed that, 16 species have proved potential anticancer properties due to the accumulation of various sulfur and organic compounds like S-allyl mercaptocysterin, quercetin, flavonoids, and ajoene. Sulfur components of Chinese chive (Allium tuberosum Rottl. Ex Sprengel) and Rakkyo (Allium chinense G. Don) were isolated, and the sulfur compounds account for 88 and $94 \%$ of the total volatiles in the isolated extract of Chinese chive and rakkyo, respectively. It has been reported various furostanol saponins, steroidal saponins, and spirostane saponins in isolated extract of it (Ren et al., 2010). On the basis of traditional Chinese medicine, onions special features are warm and hot tastes, together with functions such as warming the lungs to reduce phlegm, warming the stomach during digestion, detoxifying and destroying intestinal 
worms, decreasing swelling and soreness, and decreasing blood pressure and blood lipids (Yang et al., 2018). Several studies have shown that preparations from Xiebai show a number of biological activities, including antiatherogenic, hypolipidemic, anti-platelet aggregation, antihypertension, antioxidant and analgesic effects ( $\mathrm{He}$ et al., 2018). Xiebai as a food is often pickled as a pleasing seasoning or cooked with other ingredients to afford various delicious Chinese dishes, providing nutrition and health benefits, and traditionally it is used in combination with other herbs, in the treatment of multiple diseases of cardiovascular, respiratory and gastrointestinal systems (He et al., 2018). Sulfur compounds from alliums have played a key role in defense. Asemani et al. (2019) concluded that chemical constituents of Allium genus are involved in various mechanisms such as hindering cell cycle, inhibiting signaling pathways, inducing apoptosis, and antioxidant activity interfere with diverse stages of formation, growth, differentiation, and metastasis of cancer cells. Zhou et al. (2011) reported that the high consumption of Allium genus reduced the risk for various cancers. Yu et al. (2015) provides evidence for the cytotoxicity of $A$. chinense saponins (ACSs) and a strong foundation for further research to establish the theoretical basis for cell death and help in the design and development of new anticancer drugs. They have declared that ACSs induced morphological changes, accelerated cell death and exhibited concentration dependence, inhibited cell proliferation and exhibited dose dependence, inhibited the migration rates of B16 and 4T1 cells, inhibited cell colony formation and exhibited dose dependence, inhibition of tyrosinase activity of B16 cells treated with ACSs, ACSs inhibited tumor growth and protected the liver and spleen against injury. They have reported that Allium genus maybe the promising dietotherapeutic vegetables and organopolysulfides as well as quercetin mechanism in the treatment of chronic diseases. Lin et al. (2016) showed that ethanol extract from $A$. chinense showed notable antioxidant activity, and its high-dose essential oil extract both meaningfully reduce serum and hepatic total cholesterol, triglyceride, and low-density lipoprotein levels and increased serum and hepatic total cholesterol, triglyceride, and lowdensity lipoprotein levels and increased serum high-density lipoprotein levels in high fat-diet Wistar rats. Yang et al. (2018) implied that onion oil has anti-obesity properties that can counteract the effects of a high-fat diet (HFD) on body weight, adipose tissue weight and serum lipid profiles. Liu et al. (2014) found that the essential oil of $A$. chinensis and the major constituents demonstrated strong contact and fumigant toxicity against the booklice; they have suggested that the essential oil of $A$. chinense maybe recommended effectively in pest control programs. 


\section{Conclusions}

Shallot is a horticultural commodity belonging to spice vegetables. Shallots (Allium ascalonicum L.) are a perennial crop that is grown as an annual for its cluster of small bulbs or cloves. Persian shallot is native and endemic of Iran and grows as a wild plant across Zagross mountains at high elevations. Shallot is an important source of carbohydrate, vitamin A, B, and C. Phenolic compound in Shallot consist of gallic acid, eriodictyol, apigenin, isoquercetin, kaempferol, quercetin, rutin, catechin and tannic acid. The most important health benefits of shallots are cut cancer risk, improve heart health, aid detoxification, help control diabetes, improve brain health, help to fight obesity and treat allergies, boost bone health, maintain vision health, boost immunity, improve skin health, increase abdominal health and keep hair healthy. The dominants medicinal properties of Persian shallot are antibiotic properties, hypolipidemic properties, anticancer properties, antioxidant properties, hypoglycemic properties, kidney protective properties and hepatoprotective properties. Chinese onion (Allium chinense) widely cultivated as a vegetable and native to China. Its bulbs are commonly processed into pickles and spices. The bulb is anthelmintic, anti-inflammatory, antiseptic, antispasmodic, carminative, diuretic, expectorant, febrifuge, hypoglycaemic, hyptensive, lithontripic, stomachic and tonic. It can also use to prevent oral infection and tooth decay. The most important chemical constituents of the essential oil derived from Allium chinense are 1) dimethyl disulfide, 2) diallyl sulfide, 3) allyl isothiocyanate, 4) methyl allyl disulfide, 5) methyl propyl disulfide, 6) $\alpha$-Pinene, 7) dimethyl trisulfide, 8) $\beta$-Pinene, 9) 1,3-Dithiane, 10) limonene, 11) diallyl disulfide, 12) linalool, 13) methyl allyl trisulfide, 14) methyl propyl trisulfide, 15) dimethyl tetrasulfide, 16) diallyl trisulfide, 17) diallyl thiosulfinate, and 18) allyl methyl tetrasulfide. Integration of traditional medicine into conventional medicine will provide much more promises for the future. This review article allowed verifying shallot and Chinese onion as sources of compounds with valuable nutritional and bioactive properties with great ability for incorporation into foods with functional properties.

\section{Acknowledgements}

The authors are thankful to Qi Institute and Faculty of Biotechnology, Chinese Academy of Agricultural Science for financing the research expenses.

\section{Conflict of Interests}

The authors declare that there are no conflicts of interest related to this article.

\section{References}

Asemani Y, Zamani N, Bayat M, Amirghofran Z (2019). Allium vegetables for possible future of cancer treatment. Phytotherapy Research 33(12):3019-3039.

Chen $\mathrm{CH}$, Chou TW, Cheng LH, Ho CW (2011). In vitro anti-adenoviral activity of five Allium plants. Journal of the Taiwan Institute of Chemical Engineers 42(2):228-232.

Ebrahimi R, Zamani ZA, Kashi AAK, Jabari A (2008). Comparison of fatty acids, mineral elements of 17 Iranian shallot landraces (Allium hirtifolium Boiss.). Iranian Journal of Food Science and Technology 5(1):61-68.

Ebrahimi R, Zamani Z, Kashi A (2009). Genetic diversity evaluation of wild Persian shallot (Allium hirtifolium Boiss.) using morphological and RAPD markers. Scientia Horticulturae 4(17):345-351.

Falahati M, Fateh R, Sharifinia S (2011). Anti-candidal effect of shallot against chronic candidiasis. Iranian Journal of Pharmacology and Therapeutics 10:49-51. 
Farajii M, Roozbeh Nasiraie L, Farhoodi M (2018). Antibacterial effect of ethanolic extract shallot (Allium Hirtifolium) on the clostridium botulinum and staphylococcus aureus and organoleptic prospertise of liquid curd. Journal of Nutrition Sciences and Food Technology 12(4):73-82.

Fattorusso E, Iorizzi M, Lanzotti V, Taglialatela-Scafati O (2002). Chemical composition of shallot (Allium ascalonicum Hort.). Journal of Agricultural and Food Chemistry 50(2):5686-5690.

Ge J, Hu Y, Guo L, Wang C, Sun W, Shahrajabian MH (2018). Effects of GA 3 and ABA on the germination of dormant oat seeds. Cercetari Agronomice in Moldova 3(175):25-41.

Golubkina N, Zamana S, Seredin T, Poluboyarinov P, Sokolov S, Baranova H, ... Caruso G (2019). Effect of selenium biofortification and beneficial microorganism inoculation on yield, quality and antioxidant properties of shallot bulbs. Plants $8(102): 1-18$.

He Q, Huang S, Wu Y, Zhang W, Wang F, Cao J, ... Ou W (2018). Comparative study on the composition of free amino acids derivatives in the two botanical origins of an edible Chinese herb Xiebai, i.e. Allium chinense G. Don and Allium macrostemon Bunge species. Food Research International 106:446-457.

Jalal R, Bagheri SM, Moghimi A (2010). The effect of Iranian shallot or garlic aqueous extracts on learning, memory and serum biochemical variables in fructose-fed Wistar rats. Iranian Journal of Basic Medical Sciences 14(3):284-289.

Kazemian S, Karimi A, Pilevariyan A, Ghandi A (2017). The effect of hydro-alcoholic shallots extract testis and spermatogenesis in balb/c mice. Journal of Zanjan University of Medical Sciences and Health Services 25(109):5062.

Khoshkharam M, Shahrajabian MH, Sun W, Cheng Q (2019). Survey the allelopathic effects of tobacco (Nicotiana Tabacum L.) on corn (Zea mays L.) growth and germination. Cercetari Agronomice in Moldova 4(180):332-340.

Kongkaew W, Phichai K (2010). The use of medicinal plants extracts and antagonistic bacteria to control green mold disease (Trichoderma ssp.) of Yanagi mushroom. RMUTTO Research Journal 3:26-37.

Krejcova P, Kucerova P, Stafford GI, Jager AK, Kubec R (2014). Anti-inflammatory and neutological activity of pyrithione and related sulfur-containing pyridine $N$-oxides from Persian shallot (Allium stipitatum). Journal of Ethnopharmacology 154(1):176-182.

Leelarungrayub N, Chanarat N, Rattanapanone V (2004). Potential activity of Thai shallot (Allium ascalonicum L.) extract on the prevention of hemolysis and glutathione depletion in human erythrocyte from oxidative stress. CMU Journal 3(3):225-234.

Leelarungrayub N, Rattanapanone V, Chanarat N, Gebicki JM (2006). Quantitative evaluation of the antioxidant properties of garlic and shallot preparations. Nutrition 22(3):266-274.

Lin YP, Lin L, Yeh HY, Chuang CH, Tseng SW, Yen YH (2016). Antihyperlipidemic activity of Allium chinense bulbs. Journal of Food and Drug Analysis 24(3):516-526.

Liu XC, Lu XN, Liu QZ, Liu ZL (2014). Evaluation of insecticidal activity of the essential oil of Allium chinense G. Don and its major constituents against Liposcelis bostrychophila Badonnel. Journal of Asia-Pacific Entomology 17:853856.

Moradi Y, Moradi-Sardareh H, Ghasemi H, Mohamadi N, Moradi MN, Hosseini-Zijoud SM (2013). Medicinal properties of Persian shallot. European Journal of Experimental Biology 3(1):371-379.

Ogbaji PO, Shahrajabian MH, Xue X (2013). Changes in germination and primarily growth of three cultivars of tomato under diatomite and soil materials in auto-irrigation system. International Journal of Biology 5(3):80.

Ogbaji PO, Li J, Xue X, Shahrajabian MH, Egrinya EA (2018). Impact of bio-fertilizer or nutrient on Spinach (Spinacea Oleracea) growth and yield in some province soils of P.R. China. Cercetari Agronomice in Moldova 2(174):43-52.

Pan Y, Zheng YM, Ho WS (2018). Effect of quercetin glucosides from Allium extracts on HepG2, PC-3 and HT-29 cancer cell lines. Oncology Letters 15(4):4657-4661.

Phaiphan A, Panichakool P, Jinawan S, Penjumras P (2019). Effects of heat and shallot (Allium ascalonicum L.) supplementation on nutritional quality and enzymatic browning of apple juice. Journal of Food Science and Technology-Mysore 1-8.

Raeisi S, Sharifi-Rad M, Quek SY, Shabanpour B, Sharifi-Rad J (2016). Evaluation of antioxidant and antimicrobial effects of shallot (Allium ascalonicum L.) fruit and ajwain (Trachyspermum ammi (L.) Sprague) seed extracts in semi-fried coated rainbow trout (Oncorhynchus mykiss) fillets for shelf-life extension. LWT- Doof Science and Technology 65:112-121. 
Rattanachaikunsopon P, Phumkhachorn P (2009). Shallot (Allium ascalonicum L.) oil: diallyl sulfide content and antimicrobial activity against food-borne pathogenic bacteria. African Journal of Microbiology Research 3(11):747-750.

Razieh J, Bagheri SM, Moghimi A (2011). The effect of Iranian shallot or garlic aqueous extract on learning, memory a serum biochemical variable in fructose-fed Wistar rats. Iranian Journal of Basic Medical Sciences 14(3):284-289.

Ren G, Qiao HX, Yang J, Zhou CX (2010). Protective effects of steroids from Allium chinense against $\mathrm{H}_{2} \mathrm{O}_{2}$-induced oxidative stress in rat cardiac H9C2 cells. Phytotherapy Research 24:404-409.

Rohn S, Buchner N, Driemel G, Rauser M, Kroh LW (2007). Thermal degradation of onion quercetin glucosides under roasting conditions. Journal of Agricultural and Food Chemistry 55:1568-1573.

Sadat Hosseini F, Falahati-pour SK, Hajizadeh MR, Khoshdel A, Mirzaei MR, Ahmadirad H, Behroozi R, Jafari N, Mahmoodi M (2017). Persian shallot, Allium hirtifolium Boiss, induced apoptosis in human hepatocellular carcinoma cells. Cytotechnology 69:551-563.

Setyadjit, Sukasih E (2015). Effect of addition of filler on the production of shallot (Allium cepar var. ascalonicum L.) powder with drum dryer. Procedia Food Science 3:396-408.

Shahrajabian MH, Sun W, Cheng Q (2018). A review of goji berry (Lycium barbarum) in traditional Chinese medicine as a promising organic superfood and superfruit in modern industry. Academia Journal of Medicinal Plants 6(12):437-445.

Shahrajabian MH, Sun W, Cheng Q (2019a). The influence of traditional Iranian and Chinese medicine on western and Islamic countries. Asian Journal of Medical and Biological Research 5(2):94-99.

Shahrajabian MH, Sun W, Cheng Q (2019b). Modern pharmacological actions of Longan fruits and their usages in traditional herbal remedies. Journal of Medicinal Plant Studies 7(4):179-185.

Shahrajabian MH, Sun W, Cheng Q (2019c). Jujube, a super-fruit in traditional Chinese medicine, heading for modern pharmacological science. Journal of Medicinal Plant Studies 7(4):173-178.

Shahrajabian MH, Khoshkharam M, Sun W, Cheng Q (2019d). The effect of pretreatment factors on seed germination and seedling growth of anise (Pimpinella anisum L.) Middle East Journal of Science 5(1):86-93.

Shahrajabian MH, Sun W, Cheng Q (2019e). A review of ginseng species in different regions as a multipurpose herb in traditional Chinese medicine, modern herbology and pharmacological science. Journal of Medicinal Plants Research 13(10):213-226.

Shahrajabian MH, Sun W, Cheng Q (2019f). Clinical aspects and health benefits of ginger (Zingiber officinale) in both traditional Chinese medicine and modern industry. Acta Agriculturae Scandinavica, Section B-Soil \& Plant Science 69(6):546-556.

Shahrajabian MH, Sun W, Cheng Q (2019g). The power of natural Chinese medicine, ginger and ginseng root in an organic life. Middle-East Journal of Scientific Research 27(1):6471.

Shahrajabian MH, Sun W, Cheng Q (2020a). A short review of goji berry, ginger, ginseng and astragalus in traditional Chinese and Asian medicine. Black Sea Journal of Health Science 3(2):1-2.

Shahrajabian MH, Sun W, Cheng Q (2020b). Chinese star anise (Illicium verum) and pyrethrum (Chrysanthemum cineraiifolium) as natural alternatives for organic farming and health care- A review. Australian Journal of Crop Sciences 14(03):517-523.

Shahrajabian MH, Sun W, Cheng Q (2020c). Chinese herbal medicine for SARS and SARS-CoV-2 treatment and prevention, encouraging using herbal medicine for COVID-19 outbreak. Acta Agriculturae Scandinavica, Section B-Soil \& Plant Science.

Shen H, Shahrajabian MH, Chao L, Han S, Jue L, Sun W, Cheng Q, Bilian C, Zhijian W (2020). Microbial contamination database and limit standards for herbal medicine. Agrociencia 54(1):107-120.

Sittisart P, Yossan S, Prasertsan P (2017). Antifungal property of chili, shallot and garlic extracts against pathogenic fungi, Phomopsis spp., isolated from infected leaves of para rubber (Hevea brasiliensis Muell. Arg.). Agriculture and Natural Resources 51:485-491.

Soleymani A, Shahrajabian MH (2012). Response of different cultivars of fennel (Foeniculum vulgare) to irrigation and planting dates in Isfahan, Iran. Research on Crops 13(2):656-660.

Soleymani A, Shahrajabian MH (2018). Changes in germination and seedling growth of different cultivars of cumin to drought stress. Cercetari Agronomice in Moldova 1(173):91-100.

Sun W, Shahrajabian MH, Cheng Q (2019a). The insight and survey on medicinal properties and nutritive components of shallot. Journal of Medicinal Plant Research 13(18):452-457. 
Sun W, Shahrajabian MH, Cheng Q (2019b). Anise (Pimpinella anisum 1.), a dominant spice and traditional medicinal herb for both food and medicinal purposes. Cogent Biology 5(1673688):1-25.

Sun W, Shahrajabian MH, Cheng Q (2019c). Therapeutic roles of goji berry and ginseng in traditional Chinese. Journal of Nutrition and Food Security 4(4):293-305.

Sun W, Shahrajabian MH, Khoshkharam M, Cheng Q (2020a). Adaptation of acupuncture and traditional Chinese herbal medicines models because of climate change. Journal of Stress Physiology and Biochemistry 16(1):85-90.

Sun W, Shahrajabian MH, Huang Q (2020b). Soybean seeds treated with single walled carbon naotubes (SwCNTs) showed enhanced drought tolerance during germination. International Journal of Advanced Biological and Biomedical Research 8(1):9-16.

Swamy KRM, Veere Gowda R (2006). Leek and shallot. Handbook of Herbs and Spices, Woodhead Publishing Series in Food Science, Technology and Nutrition 3:365-389.

Tesfa T, Woldestsadik K, Bayu W (2015). Shallot yield, quality and shelf-life as affected by nitrogen fertilizer. International Journal of Vegetable Science 21(5):454-466.

Teshika JD, Zakariyyah AM, Zaynab T, Zengin G, Rengasamy KRR, Pandian SK, Fawzi MM (2018). Traditional and modern uses of onion bulb (Allium cepa L.): a systematic review. Critical Reviews in Food Science and Nutrition. DOI: $10.1080 / 10408398.2018 .1499074$

Wang Y, Li C, Xiang L, Huang W, He X (2016). Spirostanol saponins from Chinese onion (Allium chinense) exert pronounced anti-inflammatory and anti-proliferative activities. Journal of Functional Foods 25:208-219.

Wongmekiat O, Leelarugrayub N, Thamprasert K (2008). Beneficial effect of shallot (Allium ascalonicum L.) extract on cyclosporine nephrotoxivity in rats. Food and Chemical Toxicology 46(5):1844-1850.

Yang MM, Xu C, Kim CH, Um YC, Bah AA, Guo DP (2009). Effects of explants type, culture media and growth regulators on callus induction and plant regeneration of Chinese jiaotou (Allium chinense). Scientia Horticulturae 123:124-128.

Yang C, Li L, Yang L, Lu H, Wang S, Sun G (2018). Anti-obesity and hypolipidemic effects of garlic oil and onion oil in rats fed a high-fat diet. Nutrition and Metabolism 15:43.

Yin M-C, Hsu P-C, Chang H-H (2006). In vitro antioxidant and antibacterial activities of shallot and scallion. Journal of Food Science 68(1):281-284.

Yu Z, Zhang T, Zhou F, Xiao X, Ding X, He H, Rang J, Quan M, Wang T, Zuo M, Xia L (2015). Anticancer activity of saponins from Allium chinense against the B16 melanoma and 4T1 breast carcinoma cell. Evidence-Based Complementary and Alternative Medicine. 2015(725023):1-12.

Zhou Y, Zhuang W, Hu W, Liu GJ, Wu TX, Wu XT (2011). Consumption of large amounts of Allium vegetables reduces risk for gastric cancer in meta-analysis. Gastroenterology 141(1):80-89.

Zhu DY, Ma YL, Thakur K, Wang CH, Wang H, Ren YF, ... Wei ZJ (2018). Effects of extraction methods on the rheological properties of polysaccharides from onion (Allium cepa L.). International Journal of Biological Macromolecules 112:22-32.

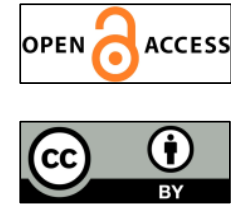

The journal offers free, immediate, and unrestricted access to peer-reviewed research and scholarly work. Users are allowed to read, download, copy, distribute, print, search, or link to the full texts of the articles, or use them for any other lawful purpose, without asking prior permission from the publisher or the author.

License - Articles published in Notulae Scientia Biologicae are Open-Access, distributed under the terms and conditions of the Creative Commons Attribution (CC BY 4.0) License.

(C) Articles by the authors; SHST, Cluj-Napoca, Romania. The journal allows the author(s) to hold the copyright/to retain publishing rights without restriction. 